\title{
Eliminação da consolidação proporcional: análise da adequação da decisão do IASB
}

Elimination of the proportionate consolidation method: analysis of the adequacy of the IASB' decision

Eliminación de la consolidación proporcional: análisis de la adecuación de la decisión del IASB

\section{Raquel Wille Sarquis}

Mestre em Controladoria e Contabilidade pela Universidade de São Paulo (FEA-USP)

Endereço: Avenida Professor Luciano Gualberto, 908 - Butantã

CEP 05508-010 - São Paulo/SP - Brasil

E-mail: raquel.sarquis@usp.br

Telefone: (11) 94147-3696

\section{Ariovaldo dos Santos}

Doutor em Controladoria e Contabilidade pela Universidade de São Paulo (USP) e Livre-

Docência em Contabilidade pela Universidade de São Paulo (USP)

Professor-Titular do Departamento de Contabilidade e Atuária da Faculdade de Economia,

Administração e Contabilidade da Universidade de São Paulo (FEA/USP)

Endereço: Avenida Professor Luciano Gualberto, 908 - Butantã

CEP 05508-010 - São Paulo/SP - Brasil

E-mail: arisanto@usp.br

Telefone: (11) 2648-6344

Artigo recebido em 07/09/2018. Revisado por pares em 25/03/2019. Reformulado em 12/04/2019. Recomendado para publicação em 12/04/2019 por Carlos Eduardo Facin Lavarda (Editor-Chefe). Publicado em 30/04/2019. 


\title{
Resumo
}

O objetivo é analisar os argumentos dos respondentes que se manifestaram durante o período de audiência pública do Exposure Draft 09 - Joint Arrangements, com o propósito de inferir sobre a adequação da decisão do IASB de eliminar a consolidação proporcional. Utilizando-se a técnica de análise de conteúdo, foram analisadas as 111 cartas enviadas para o IASB. Dessas, 107 se manifestaram sobre a eliminação da consolidação proporcional e 68 afirmaram não concordar com a decisão do IASB, evidenciando um elevado nível de rejeição. Os países com maior taxa de rejeição estão na Europa e os com maior aceitação são da Ásia. Dentre os grupos de interesse com maior rejeição estão as empresas de auditoria e as associações profissionais. Esta pesquisa argumenta que a consolidação proporcional resulta em informações contábeis de maior relevância que o MEP e que a divulgação de informações adicionais não compensará a perda informacional da consolidação proporcional.

Palavras-chave: Comment letters; IFRS 11; Joint ventures; Consolidação proporcional

\begin{abstract}
The purpose is to analyze the arguments of the respondents who sent letters during the public consultation period of the Exposure Draft 09 - Joint Arrangements, in order to infer about the adequacy of the IASB's decision to eliminate proportionate consolidation. Using the Content Analysis technique, the 111 letters sent to the IASB were analyzed. Of the 107 respondents who commented about the elimination of proportionate consolidation, 68 mentioned that they did not agree with the IASB decision, evidencing a high level of rejection. The countries with the highest rate of rejection are from Europe and with the highest level of acceptance are from Asia. The interest groups with the highest rate of rejection are audit firms and professional associations. This research argues that proportionate consolidation results in more relevant accounting information than the equity method and that the greater disclosure requirements will not compensate the information loss arising from the elimination of the proportionate consolidation.
\end{abstract}

Keywords: Comment letters; IFRS 11; Joint ventures; Proportionate consolidation

\section{Resumen}

El objetivo es analizar los argumentos de los respondientes que se manifestaron durante el período de audiencia pública del exposure draft 09 - joint arrangements, con el propósito de inferir sobre la adecuación de la decisión del iasb de eliminar la consolidación proporcional. utilizando la técnica de análisis de contenido, se analizaron las 111 cartas enviadas al iasb. de las 107 cartas que se pronunciaron sobre la eliminación de la consolidación proporcional, 68 afirmaron no concordar con la decisión del iasb, lo que resultó en un elevado nivel de rechazo. los países con mayor tasa de rechazo están en europa y los con mayor aceptación son de asia. entre los grupos de interés con mayor rechazo están las empresas de auditoría y las asociaciones profesionales. esta investigación argumenta que la consolidación proporcional resulta en informaciones contables de mayor relevancia que el método de equivalencia patrimonial y que la divulgación de informaciones adicionales no compensará la pérdida informacional ocasionada por la eliminación de la consolidación proporcional.

palabras clave: Comment letters; IFRS 11; Joint ventures; Consolidación proporcional

\section{Introdução}

O desastre ambiental ocasionado pelo rompimento das barragens de rejeitos da Samarco, ocorrido em 2015, reacendeu uma discussão bastante importante na área contábil: qual a responsabilidade da Vale e da BHP Billiton sobre as operações da Samarco? A Vale e a BHPB compartilham o controle da Samarco e, portanto, trata-se de um investimento em joint 
venture. Essa discussão resulta em um segundo questionamento: qual o método mais adequado para reconhecimento e mensuração dos investimentos em joint ventures, tendo em vista o propósito de melhor refletir os direitos e obrigações das investidoras em relação às operações da joint venture? Ainda não existe uma resposta única para esses questionamentos.

Com a aplicação da IFRS 11 - Joint Arrangements, traduzida pelo CPC 19 (R2) Negócios em Conjunto, o uso do Método de Equivalência Patrimonial (MEP) é obrigatório. Entretanto, até as demonstrações contábeis de 2012 (ou 2013, no caso dos países da União Europeia), a normatização contábil anterior (IAS 31) permitia que as empresas pudessem escolher entre o MEP e a consolidação proporcional. No Brasil, por imposição da Comissão de Valores Mobiliários (CVM), a consolidação proporcional foi mandatória até a edição da IFRS 11 .

Existia (e ainda existe) uma grande divergência de opiniões sobre qual dos dois métodos é o mais adequado. No MEP a empresa investidora reconhece sua participação nos ativos líquidos da joint venture em uma única conta (investimento), da mesma forma que o faz para o resultado líquido (resultado de equivalência patrimonial). Por outro lado, na consolidação proporcional, a investidora reconhece sua participação proporcional em cada um dos ativos, passivos, receitas e despesas da joint venture nas suas próprias demonstrações contábeis, em cada uma das contas correspondentes, e não apenas pelo valor líquido, como feito no MEP.

Antes da adoção da IFRS 11, o MEP predominava em países de origem anglo-saxônica, como Reino Unido, Austrália e Nova Zelândia, assim como em Hong Kong, Kuwait e Malásia. A consolidação proporcional, por sua vez, era mais frequentemente utilizada em países da Europa Continental, como França, Espanha e Polônia, além dos países da América Latina, como Brasil e México (SARQUIS, 2019).

A adoção de um método em detrimento de outro resulta em diferenças significativas nos valores reportados pelas empresas investidoras (FURUTA, 2005; SANTOS, 2011; RICHARDSON; ROUBI; SOONAWALLA, 2012; SARQUIS; SANTOS, 2018). Especificamente, a troca da consolidação proporcional para o MEP, em geral, reduz os valores de ativos, passivos, receitas e despesas, sendo que essa redução pode ser bastante material. Por exemplo, quando a Itaúsa adotou a IFRS 11 e deixou de utilizar a consolidação proporcional, o valor do seu passivo reduziu de $\$ 331,3$ bilhões para apenas $\$ 6,4$ bilhões de reais. Óbvio, essa redução de expressivos $98 \%$ foi decorrente da "simples" alteração na prática contábil e não de modificações no nível de endividamento da empresa. O caso dos impactos da IFRS 11 na Itaúsa foi analisado em detalhes por Sarquis e Santos (2018).

O fato de a troca da consolidação proporcional para o MEP resultar em diferenças significativas nos valores reportados pelas empresas ressalta ainda mais a importância da discussão sobre qual seria a prática contábil mais adequada. Essas diferenças afetam diversos indicadores econômico-financeiros e, consequentemente, o processo de análise e tomada de decisão. Outra questão importante é o impacto nas cláusulas restritivas (covenants) dos contratos de empréstimos e financiamentos.

Existem argumentos favoráveis e contrários aos dois métodos, conforme será evidenciado no Tópico 2.2. Para Richardson, Roubi e Soonawalla (2012), o ponto principal da discussão é se a empresa investidora deve consolidar ativos e passivos controlados em conjunto com seus ativos e passivos controlados integralmente. Ou seja, se a controladora em conjunto de fato controla e tem obrigações sobre os ativos e passivos conjuntos, respectivamente, que justifiquem sua inclusão no balanço.

Além da divergência de opiniões sobre qual seria o método mais adequado, também existia uma grande variabilidade na prática contábil utilizada para reconhecimento e mensuração dos investimentos em joint ventures não apenas entre países, mas entre empresas do mesmo país. Buscando reduzir essa divergência, o IASB e o FASB estabeleceram um projeto de convergência de curto prazo com o intuito de reduzir as diferenças entre as normas 
internacionais (IFRS) e as americanas (USGAAP). Inclusive, é importante mencionar que essa era uma das principais diferenças conceituais entre esses dois órgãos reguladores, já que o FASB nunca permitiu o uso da consolidação proporcional.

Como resultado desse projeto, em maio de 2011 o IASB emitiu a IFRS 11 - Joint Arrangements, em conjunto com as IFRS 10 - Consolidated Financial Statements e IFRS 12 Disclosure of Interests in Other Entities. O Tópico 2.1 descreve as principais alterações trazidas pela IFRS 11, entretanto, a alteração mais relevante foi justamente a eliminação da consolidação proporcional como uma alternativa válida para reconhecimento dos investimentos em joint ventures. Após a IFRS 11 todos os investimentos classificados como joint ventures passaram a ser avaliados pelo MEP.

Entretanto, essa decisão do IASB de eliminar a possibilidade de consolidação proporcional foi bastante polêmica. Além do potencial de produzir um impacto relevante nas demonstrações contábeis das empresas investidoras, existem evidências de que a consolidação proporcional pode fornecer informações contábeis mais relevantes e com maior capacidade preditiva do que o MEP (GRAHAM; KING; MORRILL, 2003). Adicionalmente, a maior parte dos indivíduos e organizações que enviaram cartas para o IASB, durante o período de audiência pública da IFRS 11, se manifestou contrária à eliminação da consolidação proporcional. Uma das principais preocupações é que as empresas passem a se utilizar dos investimentos em joint ventures para manter dívidas fora de suas demonstrações contábeis e, nesses casos, o MEP poderá não refletir de forma adequada a situação econômico-financeira das empresas investidoras.

Apesar de todas as evidências contrárias, o IASB manteve sua decisão de eliminar a consolidação proporcional. Dentre as principais justificativas do IASB está o fato de que a existência da escolha contábil para reconhecimento e mensuração dos investimentos em joint ventures estaria prejudicando a comparabilidade das informações contábeis e que a opção pela consolidação proporcional poderia levar ao reconhecimento de ativos que não são controlados pela entidade e de passivos que não são realmente obrigações da entidade, contrariando as definições de ativo e passivo da Estrutura Conceitual. Por consequência, a utilização do MEP passou a ser obrigatória. O Tópico 2.3 aborda com maior profundidade a discussão sobre esse possível conflito entre a consolidação proporcional e a Estrutura Conceitual.

Nesse contexto, a presente pesquisa busca explorar essa questão por meio da análise das comment letters que foram enviadas para o IASB durante o período de audiência pública da IFRS 11. Portanto, este trabalho busca responder a seguinte questão de pesquisa: "Quais as percepções e argumentos dos usuários que se manifestaram, por meio de cartas enviadas ao IASB durante o periodo de audiência pública, sobre o Exposure Draft 09 - Joint Arrangements?"

Especificamente, foram estabelecidos dois objetivos principais. O primeiro deles foi analisar os argumentos apresentados pelos usuários que enviaram cartas para o IASB durante o período de audiência pública do Exposure Draft 09, tanto conforme o grupo de interesse quanto o país de origem. Utilizando a técnica de análise de conteúdo, foram analisadas por completo as 111 cartas enviadas ao IASB durante o período de audiência pública. O propósito dessa análise é não apenas verificar a quantidade de cartas em que os respondentes concordavam ou não com as alterações propostas pelo IASB na IFRS 11, mas também discutir quais foram os principais argumentos utilizados pelos respondentes, tanto para concordar quanto para discordar das referidas alterações. Com base nesses comentários e argumentos, o segundo objetivo desta pesquisa foi inferir a respeito da adequação ou não da decisão do IASB de eliminar a consolidação proporcional e sobre suas consequências.

Acredita-se que essa discussão é relevante, pois a decisão do IASB de eliminar a consolidação proporcional pode ter consequências práticas importantes, sendo que o caso da Samarco ilustra bem essa questão. A Vale menciona em sua demonstração contábil que, 
conforme a legislação brasileira e os termos do acordo da joint venture, não tem a obrigação de prover recursos para a Samarco. Assim, seguindo as determinações da IFRS 11, a Vale não teria direitos sobre os ativos e obrigações sobre os passivos da Samarco e, portanto, tal investimento foi classificado como joint venture e contabilizado pelo MEP. Entretanto, mesmo sem a obrigação legal, tanto a Vale quanto a BHPB estão sendo responsabilizadas judicialmente pelo Ministério Público Federal pelo rompimento das barragens de rejeitos da Samarco. Além disso, também passaram a ser corresponsáveis pelas dívidas da Samarco, tanto é que a Vale está reconhecendo uma provisão em seu passivo. Tais obrigações podem afetar a saúde financeira da Vale e da BHPB e não estavam sendo reconhecidas de forma adequada em suas demonstrações contábeis, já que o MEP estava sendo utilizado.

Tal exemplo evidencia claramente que, mesmo não tendo obrigações legais, em algumas situações, as investidoras em conjunto podem ser corresponsáveis pelas dívidas da joint venture. E essas dívidas deveriam estar reconhecidas nas suas demonstrações contábeis. Tais evidências levantam questionamentos sobre se a decisão do IASB de eliminar a consolidação proporcional foi adequada, já que as empresas estão mantendo fora de seus balanços dívidas que podem comprometer sua situação financeira. Essa é uma das principais críticas ao MEP.

Cabe ressaltar que as consequências da adoção de uma nova norma não serão integralmente observadas no primeiro ano de adoção, mas sim após certo período, já que as empresas precisam se adaptar às alterações propostas pela nova norma. Acredita-se que o fato de uma norma já estar em vigor, não significa que ela não será mais alterada pelo órgão regulador, e nem que as discussões sobre a sua adequação, relevância e impacto devem ser esquecidas. Pelo contrário. A academia exerce um papel relevante em discutir não apenas as normas que estão em desenvolvimento, mas também aquelas que já foram emitidas, com a finalidade de sinalizar para o órgão regulador a existência (ou não) de pontos problemáticos. E essa situação é particularmente evidente no caso da IFRS 11.

Um indício de que essa discussão ainda é necessária, é o fato de que algumas empresas continuam utilizando, de forma voluntária, a consolidação proporcional para divulgar suas informações financeiras no relatório da administração, em nota de informações por segmento operacional ou como informação adicional, já que este é o tipo de informação utilizada para fins gerenciais. No Brasil esse são os casos, por exemplo, da Companhia Siderúrgica Nacional (CSN), da Cosan, do Bradesco e da Klabin. Porém, também existem empresas na África do Sul (African Rainbow Minerals), no Canadá (AKITA Drilling, Glacier Media e GVIC Communications) e no Reino Unido (Hammerson, Rurelec, Tate \& Lyle, Telford Homes, Intu Properties e John Wood Group).

Acredita-se que este trabalho pode contribuir para a literatura contábil sobre o método mais adequado para reconhecimento dos investimentos em joint ventures. Existem alguns trabalhos que analisaram parte das comment letters enviadas em resposta ao Exposure Draft 09, como Souza, Tavares, Anjos e Lopes (2015), mas este trabalho se diferencia da literatura anterior por quatro motivos principais. Primeiro, este trabalho discute não apenas a questão 3 do Exposure Draft 09, sobre a eliminação da consolidação proporcional, mas também as questões relacionadas aos conceitos e terminologias, ao Princípio Geral proposto na IFRS 11 e também sobre as exigências de divulgação (questões 1, 2 e 4), proporcionando uma visão mais abrangente sobre as alterações propostas pelo IASB no Exposure Draft 09. Segundo, a presente pesquisa analisou todas as comment letters que foram enviadas ao IASB e realizou as análises não apenas conforme o país de origem, mas também conforme o tipo de respondente (órgão regulador, empresa de auditoria, empresa não financeira, etc.). Terceiro, este artigo apresenta também os argumentos utilizados pelos respondentes para concordar/discordar das alterações propostas pelo IASB. Por último, acredita-se que um diferencial importante deste trabalho é justamente a utilização de um posicionamento crítico para argumentar qual dos dois métodos, na opinião dos autores (devidamente fundamentada e justificada), é considerado o mais 
adequado para reconhecimento dos investimentos em joint ventures.

Ainda, esta pesquisa pode contribuir principalmente para os órgãos reguladores, ao fornecer indícios que o IASB poderá levar em consideração durante o Post-Implementation Review (PIR) da IFRS 11. Mesmo que as informações das comment letters já sejam de conhecimento do IASB, esta pesquisa contribui ao levantar a discussão sobre a existência de possíveis consequências indesejadas em decorrência das alterações propostas, que poderão auxiliar o órgão regulador a avaliar a adequação ou não da sua decisão de eliminar a consolidação proporcional.

Além dessa introdução, este trabalho está segregado em outras quatro seções. A seção 2 apresenta o referencial teórico utilizado. Na seção 3 é feita a descrição dos procedimentos metodológicos. As seções 4 e 5 apresentam as análises das cartas enviadas para o IASB e as conclusões e considerações finais do trabalho, respectivamente.

\section{Referencial Teórico}

\subsection{Alterações com a adoção da IFRS 11}

A emissão da IFRS 11 - Joint Arrangements substituiu a IAS 31 - Interests in Joint Ventures e representa a maior revisão feita nessa norma desde quando ela foi inicialmente emitida em 1990, sendo que as alterações foram tanto em termos conceituais quanto práticos.

De forma bastante resumida, o termo joint venture deixou de ser utilizado para descrever o conjunto de investimentos com controle compartilhado (após a IFRS 11, o termo joint arrangements é adotado) e passou a ser utilizado apenas para designar uma das classificações de negócios em conjunto: investimentos em entidades controladas em conjunto.

Ocorreram duas alterações relevantes na classificação dos negócios em conjunto. A primeira delas é a redução na quantidade de categorias. A IAS 31 determinava três categorias (operações controladas em conjunto; ativos controlados em conjunto e entidades controladas em conjunto) e com a adoção da IFRS 11 passaram a existir apenas duas categorias: operações em conjunto e joint ventures.

A segunda alteração é que a IAS 31 determinava que o elemento principal para a classificação era a existência ou não de uma entidade jurídica separada. Quando existia uma entidade jurídica separada, o investimento deveria ser classificado como uma entidade controlada em conjunto. Com a IFRS 11, a classificação depende da avaliação dos direitos e obrigações decorrentes do negócio, que inclui outros fatores e circunstâncias, além da existência de uma entidade jurídica separada. Se essa avaliação indicar que as partes do acordo têm direitos sobre os ativos e obrigações sobre os passivos, o negócio em conjunto deve ser classificado como uma operação em conjunto. Caso o direito seja apenas sobre os ativos líquidos, o negócio em conjunto deve ser classificado como joint venture.

Em relação ao método de contabilização, a principal alteração foi para os negócios em conjunto classificados como joint ventures. A IAS 31 permitia a escolha entre o MEP e a consolidação proporcional. Porém, o IASB acreditava que a existência desse tipo de escolha poderia levar a situações em que investimentos similares fossem reconhecidos de forma diferente, prejudicando a comparabilidade. Portanto, quando da emissão da IFRS 11, o IASB eliminou a possibilidade de utilizar a consolidação proporcional para reconhecimento desses investimentos, tornando o MEP obrigatório.

Fica evidente que as empresas mais impactadas com a IFRS 11 foram aquelas que possuíam investimento em entidade controlada em conjunto, conforme a IAS 31, que optavam por utilizar a consolidação proporcional, e que passam a ser classificados como investimentos em joint ventures, pela IFRS 11. Além das alterações conceituais, tais empresas tiveram que alterar o método de contabilização até então utilizado, da consolidação proporcional para o 
MEP. Consequentemente, apresentaram reduções nos valores de ativo, passivos, receitas e despesas.

\subsection{Consolidação Proporcional versus Equivalência Patrimonial}

Para compreender a lógica que está por trás da consolidação proporcional e do MEP, é preciso levar em consideração o nível de interação entre as investidoras e a investida. No caso do MEP, a lógica é que a investidora possui direitos apenas sobre os ativos líquidos da joint venture, ou seja, apenas sobre o resultado líquido gerado pelo conjunto de ativos e passivos da joint venture. Consequentemente, a investidora reconhecerá sua participação nos ativos líquidos da joint venture em uma única conta do balanço patrimonial (investimentos), assim como fará com o resultado do período (resultado de equivalência patrimonial, na DRE).

Por outro lado, a lógica da consolidação proporcional é que a investidora tem direitos sobre os ativos e obrigações sobre os passivos da joint venture, de forma proporcional à sua participação. Assim, a investidora reconhece os ativos, passivos, receitas e despesas proporcionais à sua participação nas suas próprias demonstrações contábeis, em cada uma das contas correspondentes.

A principal diferença entre os dois métodos é que, na consolidação proporcional, o valor do investimento é distribuído, linha a linha, para cada ativo e passivo do balanço patrimonial da investidora, bem como o resultado de equivalência patrimonial é distribuído, linha a linha, para cada receita e despesa que integra o resultado do período (GELBCKE; SANTOS; IUDÍCIBUS; MARTINS, 2018). Assim, utilização do MEP em detrimento da consolidação proporcional resulta em redução nos valores de ativos, passivos, receitas e despesas reconhecidos nas demonstrações contábeis das investidoras (exceto quando da existência de volumes significativos de operações entre a investidora e a joint venture).

$\mathrm{O}$ efeito da diferença entre o MEP e a consolidação proporcional nos valores reportados pelas empresas pode ser bastante relevante (FURUTA, 2005; SANTOS, 2011; LEITNERHANETSEDER; STOCKINGER, 2014). Conforme Sarquis e Santos (2018), um conjunto de ajustes contábeis é necessário para explicar as diferenças entre os dois métodos, sendo que além do reconhecimento dos valores proporcionais das joint ventures, tais ajustes também incluem o goodwill, resultados não realizados, dentre outros elementos.

Existe uma divergência de opiniões sobre qual dos dois métodos seria mais adequado para reconhecimento dos investimentos em joint ventures. O MEP é utilizado para reconhecimento dos investimentos com influência significativa (coligada), da mesma forma que a consolidação integral é utilizada quando a investidora controla a investida. Entretanto, os investimentos com controle compartilhado (joint venture) ficam no meio do caminho, pois o nível de interação das investidoras com a joint venture é muito maior do que apenas a influência significativa, mas controle compartilhado não significa controle integral para que a consolidação pudesse ser utilizada. Nesse sentido, é possível questionar se as investidoras que compartilham o controle da joint venture possuem direitos e obrigações proporcionais aos seus percentuais de participação sobre cada um dos ativos e passivos dessa investida (consolidação proporcional) ou apenas direitos sobre os ativos líquidos dessa joint venture (MEP).

O principal argumento utilizado pelos defensores do MEP é que a consolidação proporcional contraria as definições de ativo e passivo da Estrutura Conceitual, ao permitir o reconhecimento de ativos que não são controlados pela entidade e de passivos que não são obrigações presentes da entidade (MILBURN; CHANT, 1999; GRAHAM; KING; MORRILL, 2003). Segundo Furuta (2005), o investidor em conjunto não controla parte dos ativos da joint venture, já que não pode dar a destinação que julgar mais adequada para esses ativos, sem o consentimento unânime das demais partes envolvidas no negócio. Consequentemente, um ativo controlado em conjunto não atenderia ao conceito de ativo para ser reconhecido nas 
demonstrações contábeis das investidoras.

Por outro lado, aqueles que defendem a consolidação proporcional argumentam que esse método produz informações de maior relevância para o usuário, pois melhor reflete a natureza e a substância econômica do investimento na joint venture, ao evidenciar o nível de interação da investidora na investida, os valores da investida, bem como os riscos a que a investidora está exposta (RICHARDSON; ROUBI; SOONAWALLA, 2012; BETANCOURT; BARIL, 2013).

Ainda, argumenta-se que a consolidação proporcional impossibilita que as empresas investidoras se utilizem de joint ventures para manter dívidas fora do balanço. O MEP pode fazer com que dívidas que afetam a situação financeira das investidoras em conjunto não sejam reconhecidas nas suas demonstrações contábeis e, consequentemente, pode produzir uma visão enganosa sobre o desempenho econômico e financeiro das investidoras (REKLAU, 1977; FURUTA, 2005; LOURENÇO; CURTO, 2010; RICHARDSON; ROUBI; SOONAWALLA, 2012; BETANCOURT; BARIL, 2013).

Para Betancourt e Baril (2013), independentemente de a investidora possuir ou não responsabilidade legal sobre as dívidas da joint venture, sua reputação será claramente prejudicada se a joint venture não cumprir com as suas obrigações. Sendo assim, a investidora detém responsabilidade sobre essas dívidas, mesmo que indiretamente. Portanto, tais dívidas precisariam estar reconhecidas nas demonstrações contábeis das investidoras.

Um terceiro ponto é que o uso do MEP para reconhecimento tanto dos investimentos em joint ventures quanto em coligadas, resultaria em dois investimentos com características bastante diferentes sendo reconhecidos da mesma forma (SACCON; DIMA, 2015). Conforme mencionado anteriormente, o nível de interação entre as investidoras em conjunto e a joint venture é muito maior do que a existência de influência significativa. As demonstrações contábeis deveriam refletir essa diferença e, para tanto, os investimentos em joint ventures e coligadas deveriam ser reconhecidos utilizando práticas contábeis diferentes.

\subsection{Estrutura Conceitual}

A Estrutura Conceitual do IASB, traduzida por meio do Pronunciamento Técnico CPC 00 (R1) - Estrutura Conceitual para Elaboração e Divulgação de Relatório Contábil-Financeiro, em seu item 4.4 (a) define ativo como sendo "um recurso controlado pela entidade como resultado de eventos passados e do qual se espera que fluam futuros benefícios econômicos para a entidade".

$\mathrm{O}$ argumento de que a consolidação proporcional estaria contrariando a Estrutura Conceitual se baseia no fato de que um ativo controlado em conjunto não atenderia à definição de ativo mencionada no parágrafo anterior, principalmente em relação ao conceito de controle. Uma investidora em conjunto não pode dar a destinação que julgar mais adequada para os ativos da joint venture sem o consentimento unânime de todas as outras investidoras que compartilham o controle dessa joint venture. Consequentemente, ela não teria o "controle" integral sobre os futuros benefícios econômicos desses ativos.

Antes da IFRS 11, a IAS 31 - Interests in Joint Ventures permitia que as empresas optassem por reconhecer seus investimentos em joint ventures pelo MEP ou pela consolidação proporcional. Apesar disso, o item 40 da própria IAS 31 mencionava que o IASB (na época IASC) não recomendava o uso do MEP, pois a consolidação proporcional melhor reflete a substância econômica dos investimentos em joint ventures. Esse foi o principal argumento que a Comissão de Valores Mobiliários (CVM), desde os anos 1990, utilizou para exigir a consolidação proporcional.

Sendo assim, a recomendação do uso da consolidação proporcional, pela IAS 31, poderia estar em conflito com a definição de ativo da Estrutura Conceitual. Entretanto, é importante mencionar que a própria Estrutura Conceitual afirma que "nada nesta Estrutura 
Conceitual substitui qualquer pronunciamento Técnico, Interpretação ou Orientação" e que "pode haver um número limitado de casos em que seja observado um conflito entre esta Estrutura Conceitual e um Pronunciamento Técnico, uma Interpretação ou uma Orientação. Nesses casos, as exigências do Pronunciamento Técnico, da Interpretação ou da Orientação específicos devem prevalecer sobre esta Estrutura Conceitual". Ou seja, a recomendação da IAS 31 de utilização da consolidação proporcional deveria prevalecer sobre a Estrutura Conceitual.

Outra questão importante da Estrutura Conceitual está relacionada com o conceito de passivo. O item 4.15 da Estrutura Conceitual explica que a característica principal de um passivo é a existência de uma obrigação presente da entidade. Ainda, conforme o item 4.15, essas obrigações podem surgir não apenas por conta de exigências legais ou contratuais, mas também "de práticas usuais do negócio, de usos e costumes e do desejo de manter boas relações comerciais ou agir de maneira equitativa". Portanto, um passivo não necessariamente decorre apenas de obrigações legais. Nesse sentido, é possível argumentar que mesmo que a investidora em conjunto não possua obrigações legais sobre os passivos da joint venture, ela pode ter, mesmo que indiretamente, obrigações construtivas sobre o desempenho dessa joint venture, sendo corresponsável pelas dívidas da mesma. Consequentemente, tais obrigações deveriam ser reconhecidas nas demonstrações contábeis das investidoras.

\section{Desenho Metodológico}

Para responder à questão de pesquisa proposta, foram analisadas as cartas enviadas para o IASB, em resposta ao Exposure Draft 09 - Joint Arrangements, emitido no dia 13 de setembro de 2007. O período de audiência pública ficou aberto até 11 de janeiro de 2008, sendo que o IASB recebeu um total de 111 cartas em resposta à proposta de alteração.

Essas 111 cartas foram coletadas manualmente por meio do acesso ao site da Fundação IFRS e a técnica de Análise de Conteúdo foi utilizada para analisar as percepções e argumentos dos respondentes. Conforme Bardin (1977), a Análise de Conteúdo é um conjunto de técnicas de análise que se utiliza de procedimentos sistemáticos de descrição do conteúdo das mensagens, com a finalidade de obter indicadores quantitativos ou não, que permitam a inferência de conhecimentos relativos às mensagens (textos).

Essa técnica é bastante utilizada quando se busca realizar inferências sobre um texto (KRIPPENDORFF, 2004), que é o que se pretende fazer neste trabalho: analisar as cartas enviadas e realizar inferências sobre as percepções dos usuários e preparadores da informação contábil sobre as alterações propostas pelo IASB.

Quando emite um Exposure Draft para consulta pública, o IASB sugere algumas questões para guiar os respondentes, ao enviarem seus comentários. No caso do Exposure Draft 09, o IASB sugeriu seis questões: uma relacionada com as definições e terminologias, duas questões relacionadas com a contabilização dos investimentos em negócios em conjunto e, por fim, três questões sobre o nível de exigência de disclosure proposto.

Porém, as cartas não são padronizadas, podendo o respondente se limitar a responder as questões sugeridas pelo IASB, se pronunciar apenas sobre algumas questões, ou ainda, abordar assuntos adicionais. Para realizar as análises propostas, foram selecionadas quatro perguntas sugeridas pelo IASB, que são consideradas as mais relevantes, além da manifestação sobre a aceitação geral do Exposure Draft 09:

1. Aceitação geral da proposta do IASB;

2. Definições e terminologias (primeira questão);

3. Aprovação do princípio geral (segunda questão);

4. Eliminação do método de consolidação proporcional como uma alternativa válida para reconhecimento dos investimentos em joint ventures (terceira questão); 
5. Exigências de divulgação (quarta questão).

As análises realizadas são referentes à proposta de alteração do IASB inicialmente emitida no Exposure Draft 09 que, antes da emissão da IFRS 11 propriamente dita, sofreu algumas alterações em decorrência justamente dos comentários apresentados nas cartas recebidas. Portanto, para todas as questões em que ocorreram essas alterações, também foram descritas as principais diferenças entre o Exposure Draft 09 e a emissão da IFRS 11.

É importante reconhecer que podem existir limitações em relação ao método utilizado para análise das cartas. Assim como os demais trabalhos que utilizam a técnica de análise de conteúdo, a leitura das cartas pode ser influenciada por questões de julgamento e interpretação dos autores. Além disso, conforme mencionado anteriormente, as cartas não são padronizadas, o que pode gerar certa interferência nas análises. Por fim, os resultados também podem ser afetados por questões relacionadas com a tradução do conteúdo das cartas originais.

\section{Análise dos Resultados}

\subsection{Caracterização dos respondentes}

As 111 cartas recebidas pelo IASB durante o período de audiência pública do Exposure Draft 09 foram enviadas por representantes dos diversos grupos de interesse de 33 países. Esse número pode ser considerado um indicativo tanto da importância da norma, quanto da polêmica decorrente das alterações propostas pelo IASB. A Tabela 1 apresenta a quantidade de cartas enviadas por região geográfica e por grupos de interesse.

Tabela 1 - Distribuição das cartas enviadas por região geográfica e por grupos de interesse

\begin{tabular}{l|c|c|c|c|c|c|c|c}
\hline & $\begin{array}{c}\text { Boards e } \\
\text { reguladores }\end{array}$ & $\begin{array}{c}\text { Assoc. } \\
\text { profission. }\end{array}$ & $\begin{array}{c}\text { Inst. } \\
\text { financ. }\end{array}$ & $\begin{array}{c}\text { Empresas } \\
\text { não financ. }\end{array}$ & Auditoria & Academia & Outros & Total \\
\hline $\begin{array}{l}\text { América Norte e } \\
\text { Central }\end{array}$ & 3 & 1 & 1 & 6 & 1 & 0 & 1 & $13(12 \%)$ \\
\hline Europa & 22 & 14 & 9 & 25 & 5 & 1 & 3 & $79(71 \%)$ \\
\hline Ásia & 8 & 0 & 0 & 0 & 0 & 0 & 0 & $8(7 \%)$ \\
\hline Outros & 4 & 1 & 1 & 4 & 0 & 0 & 1 & $11(10 \%)$ \\
\hline Total & $37(33 \%)$ & $16(14,5 \%)$ & $11(10 \%)$ & $35(31,5 \%)$ & $6(5,5 \%)$ & $1(1 \%)$ & $5(4,5 \%)$ & 111 \\
\hline
\end{tabular}

Verifica-se que a maior parte das cartas foi enviada por países da Europa e, mais especificamente, pelo Reino Unido (23 cartas), França (12 cartas), Suíça (6) e Bélgica (5). Na América do Norte e Central, do total de 13 cartas, 10 foram enviadas por representantes do Canadá. Segundo Nobes (2013), a consolidação proporcional era bastante utilizada pelas empresas francesas e canadenses, o que pode explicar a quantidade de cartas enviadas por representantes desses dois países.

Apenas uma carta foi enviada pelos países da América do Sul (Venezuela). É importante observar que a quase totalidade das empresas brasileiras utilizavam a consolidação proporcional por determinação da Instrução $n^{\circ} 247$ da CVM e, portanto, o impacto da adoção da IFRS 11 nas empresas brasileiras foi bastante relevante. Apesar disso, nenhuma carta foi enviada pelo Brasil.

Os principais grupos de interesses são os próprios órgãos reguladores (33\%) e as empresas não financeiras $(31,5 \%)$, seguidos pelas associações profissionais $(14,5 \%)$ e instituições financeiras (10\%). Destaca-se a baixa participação dos acadêmicos no processo de normatização contábil: apenas uma carta foi enviada por uma Universidade da Finlândia. 


\subsection{Análise do posicionamento dos respondentes}

\subsubsection{Aceitação geral da proposta do IASB}

Mesmo não sendo um item relacionado com as perguntas sugeridas pelo IASB, 86 respondentes (do total de 111) manifestaram sua opinião, de forma geral, sobre a aceitação ou não das alterações propostas pelo IASB. Dessas 86 cartas, 67 respondentes (expressivos 78\%) mencionaram explicitamente no início da carta que são contrários à emissão da IFRS 11 da forma como foi apresentada no Exposure Draft 09. Tal número demonstra, já de início, a polêmica e insegurança dos diversos usuários das informações contábeis, em relação às alterações na normatização dos negócios em conjunto.

A Tabela 2 apresenta a distribuição das opiniões dos respondentes, conforme a região de origem e o grupo de interesse.

Tabela 2 - Posicionamento dos respondentes sobre a aceitação geral da proposta do IASB

\begin{tabular}{|c|c|c|c|c|c|c|c|c|}
\hline & \multicolumn{4}{|c|}{ América do Norte e Central } & \multicolumn{4}{|c|}{ Europa } \\
\hline & Favorável & Contra & $\mathbf{N R}^{1}$ & Total & Favorável & Contra & $\mathbf{N R}^{1}$ & Total \\
\hline Boards e reguladores & 2 & \begin{tabular}{l|}
0 \\
\end{tabular} & 1 & 3 & 1 & 16 & 5 & 22 \\
\hline Associações profissionais & 1 & 0 & 0 & 1 & 0 & 13 & 1 & 14 \\
\hline Inst. Financeiras & 0 & 1 & 0 & 1 & 0 & 8 & 1 & 9 \\
\hline Empresas não financeiras & 0 & 4 & 2 & 6 & 4 & 17 & 4 & 25 \\
\hline Empresas de auditoria & 1 & 0 & 0 & 1 & 0 & 5 & 0 & 5 \\
\hline Academia & 0 & 0 & 0 & $\mathbf{0}$ & 0 & 0 & 1 & 1 \\
\hline Outros & 0 & 0 & 1 & 1 & 0 & 0 & 3 & 3 \\
\hline \multirow[t]{3}{*}{ Total } & 4 & 5 & 4 & 13 & 5 & 59 & 15 & 79 \\
\hline & \multicolumn{4}{|c|}{ Ásia } & \multicolumn{4}{|c|}{ Outros } \\
\hline & Favorável & Contra & $\mathbf{N R}^{1}$ & Total & Favorável & Contra & $\mathbf{N R}^{1}$ & Total \\
\hline Boards e reguladores & 4 & 1 & 3 & 8 & 3 & 1 & 0 & 4 \\
\hline Associações profissionais & 0 & 0 & 0 & $\mathbf{0}$ & 0 & 1 & 0 & 1 \\
\hline Inst. Financeiras & 0 & 0 & 0 & $\mathbf{0}$ & 0 & 0 & 1 & 1 \\
\hline Empresas não financeiras & 0 & 0 & 0 & $\mathbf{0}$ & 3 & 0 & 1 & 4 \\
\hline Empresas de auditoria & 0 & 0 & 0 & $\mathbf{0}$ & 0 & 0 & 0 & $\mathbf{0}$ \\
\hline Academia & 0 & 0 & 0 & $\mathbf{0}$ & 0 & 0 & 0 & $\mathbf{0}$ \\
\hline Outros & 0 & 0 & 0 & $\mathbf{0}$ & 0 & 0 & 1 & 1 \\
\hline Total & 4 & 1 & 3 & 8 & 6 & 2 & 3 & 11 \\
\hline
\end{tabular}

(1) $\mathrm{NR}=$ Não respondeu

$\mathrm{Na}$ Europa, do total de respondentes que se pronunciaram sobre esse item, 92\% são contrários. Na América do Norte e Central esse percentual também é de expressivos $56 \%$. Do lado oposto, das cinco cartas da Ásia que se manifestaram sobre esse assunto, quatro demonstraram uma posição favorável à proposta do IASB.

Dentre os principais grupos de interesses que se manifestaram contrários estão as empresas não financeiras, associações profissionais e os próprios órgãos reguladores. Ainda, é interessante observar que das cinco empresas de auditoria da Europa, todas se manifestaram contrárias à emissão da IFRS 11 da forma como foi proposta no Exposure Draft 09.

Nota-se uma preocupação em o IASB emitir uma norma, que pode produzir efeitos relevantes para diversas empresas, de forma prematura, sem realizar as análises e aprofundamentos necessários. A PricewaterhouseCoopers mencionou que reconhece a intenção do IASB de conduzir um projeto de curto prazo visando a convergência com o FASB, mas que essa limitação no escopo do projeto impossibilitou que melhorias substanciais na representação fidedigna dos negócios em conjunto fossem obtidas. 


\subsubsection{Definições e terminologias}

A primeira questão sugerida pelo IASB no Exposure Draft 09 está relacionada com as definições e terminologias, ao questionar se os respondentes concordam com a proposta de alterar a forma pela qual os negócios em conjunto são descritos.

Pelo Exposure Draft 09, negócios em conjunto seriam definidos como um acordo contratual em que duas ou mais partes conduzem uma atividade econômica em conjunto e compartilham o processo de tomada de decisão sobre essa atividade. Observa-se que essa definição não fazia referência ao conceito de "controle", mas utilizava o termo "compartilhamento do processo de tomada de decisão" (share decision-making).

No Exposure Draft 09 o IASB mantinha a proposta de classificar os investimentos em negócios em conjunto em três categorias diferentes: (i) joint assets, (ii) joint operations e (iii) joint ventures, como já era previsto na norma anterior (IAS 31).

Considerando esses dois aspectos, a Tabela 3 apresenta a opinião dos respondentes sobre as Definições e Terminologias propostas. Verificou-se uma certa divergência de opiniões sobre essa questão, já que do total de respondentes que se pronunciaram sobre esse assunto (104 de 111 cartas), 49 foram favoráveis e 55 contrários.

Tabela 3 - Posicionamento dos respondentes sobre as definições e terminologias

\begin{tabular}{|c|c|c|c|c|c|c|c|c|}
\hline & \multicolumn{4}{|c|}{ América do Norte e Central } & \multicolumn{4}{|c|}{ Europa } \\
\hline & Concorda & Discorda & $\mathbf{N R}^{1}$ & Total & Concorda & Discorda & $\mathbf{N R}^{1}$ & Total \\
\hline Boards e reguladores & 3 & 0 & 0 & 3 & 7 & 15 & 0 & 22 \\
\hline Associações profissionais & 1 & 0 & 0 & 1 & 6 & 6 & 2 & 14 \\
\hline Inst. Financeiras & 0 & 1 & 0 & 1 & 1 & 7 & 1 & 9 \\
\hline Empresas não financeiras & 1 & 5 & 0 & 6 & 13 & 10 & 2 & 25 \\
\hline Empresas de auditoria & 1 & 0 & 0 & 1 & 0 & 5 & 0 & 5 \\
\hline Acadêmicos & 0 & 0 & 0 & $\mathbf{0}$ & 1 & 0 & 0 & 1 \\
\hline Outros & 1 & 0 & 0 & 1 & 1 & 2 & 0 & 3 \\
\hline \multirow[t]{3}{*}{ Total } & 7 & 6 & $\mathbf{0}$ & 13 & 29 & 45 & 5 & 79 \\
\hline & \multicolumn{4}{|c|}{ Ásia } & \multicolumn{4}{|c|}{ Outros } \\
\hline & Concorda & Discorda & $\mathbf{N R}^{1}$ & Total & Concorda & Discorda & $\mathbf{N R}^{1}$ & Total \\
\hline Boards e reguladores & 6 & 1 & 1 & 8 & 3 & 1 & 0 & 4 \\
\hline Associações profissionais & 0 & 0 & 0 & $\mathbf{0}$ & 0 & 1 & 0 & 1 \\
\hline Inst. Financeiras & 0 & 0 & 0 & $\mathbf{0}$ & 1 & 0 & 0 & 1 \\
\hline Empresas não financeiras & 0 & 0 & 0 & $\mathbf{0}$ & 3 & 1 & 0 & 4 \\
\hline Empresas de auditoria & 0 & 0 & 0 & $\mathbf{0}$ & 0 & 0 & 0 & $\mathbf{0}$ \\
\hline Acadêmicos & 0 & 0 & 0 & $\mathbf{0}$ & 0 & 0 & 0 & $\mathbf{0}$ \\
\hline Outros & 0 & 0 & 0 & $\mathbf{0}$ & 0 & 0 & 1 & 1 \\
\hline Total & 6 & 1 & 1 & 8 & 7 & 3 & 1 & 11 \\
\hline
\end{tabular}

"Question 1 - Do you agree with the proposal to change the way joint arrangements are described? If not, why?" (1) NR = Não respondeu

Algumas tendências podem ser observadas, em relação ao país de origem. Na Europa a maior parte das cartas $(61 \%)$ é contrária às alterações propostas nas definições e terminologias. Na América do Norte e Central não existe consenso, já que 7 se manifestaram favoráveis e 6 desfavoráveis. Por outro lado, assim como verificado no item anterior, as propostas de alteração do IASB receberam maior aceitação na Ásia ( $86 \%$ concordaram).

Analisando os grupos de interesse, observa-se que entre os órgãos reguladores, associações profissionais e empresas não financeiras, a divergência de opiniões se mantém. Entretanto, nas empresas de auditoria e instituições financeiras, o posicionamento que predominou foi o de oposição às alterações propostas. As 5 empresas de auditoria que se manifestaram contrárias são da Europa, sendo elas: PwC, Deloitte, BDO, KPMG e Ernst \& 
Young. A única empresa de auditoria que se manifestou favorável é a Provincial Auditor Saskatchewan, do Canadá.

O principal argumento utilizado em 17 das 55 cartas que se manifestaram contrárias é que os respondentes não acreditam que existem problemas com as definições propostas na IAS 31 que justificassem as alterações sugeridas pelo IASB. Essas alterações estariam apenas trazendo confusão, sem resultar em melhoria na representação fidedigna.

A definição de negócios em conjunto inicialmente proposta pelo IASB incluía o termo "acordo contratual" e, portanto, 7 cartas mencionaram que não concordam, pois o foco está muito voltado para a existência de um acordo contratual, esquecendo que podem existir outras formas de negócio que não obrigatoriamente estão limitadas a existência de um contrato.

Ainda, 9 cartas mencionam que na definição proposta de negócios em conjunto, a ideia de controle conjunto foi substituída pelo conceito de compartilhamento do processo de tomada de decisão e que isso estaria eliminando a necessidade de existência de controle para se caracterizar como um negócio em conjunto. Esses respondentes também argumentaram que, além de não especificar que tipo de tomada de decisão requer o compartilhamento, a definição também sugere que todas as partes devem concordar com a decisão, sendo que algumas partes podem participar do negócio em conjunto, mas não do compartilhamento do controle. Esse ponto foi levantado pela Anglo American (do Reino Unido), que explica que no seu setor de atuação (mineração) essa é uma situação comum.

A falta de clareza sobre as definições e terminologias foi mencionada por 39 das 104 cartas que se pronunciaram, já que seriam muito teóricas e de difícil aplicação prática. Com as críticas recebidas, o IASB fez algumas alterações:

1. Apresentação de guias de aplicação, que auxiliam as empresas a avaliar os direitos e obrigações decorrentes do acordo e a classificar os seus investimentos.

2. Agrupamento das categorias "ativos em conjunto" e "operações em conjunto" em uma única categoria, denominada apenas de "operações em conjunto".

3. Alteração nas definições de negócios em conjunto, para inclusão do termo "controle conjunto" e para a eliminação do termo "acordo contratual".

\subsubsection{Princípio geral}

O segundo ponto levantado pelo IASB questiona se os respondentes concordam com o princípio geral, que determina que as partes de um negócio em conjunto devem reconhecer os seus direitos e obrigações contratuais decorrentes do negócio. Também questiona se as propostas apresentadas no Exposure Draft 09 são consistentes com esse princípio.

A Tabela 4 apresenta o posicionamento dos respondentes. Assim como no item anterior, verificou-se a existência de divergência de opiniões entre os respondentes. Do total de 99 cartas que se pronunciaram sobre esse item, $48 \%$ afirmaram concordar com o princípio e $52 \%$ demonstraram posição contrária.

Das 68 cartas da Europa que se pronunciaram, 43 manifestaram insatisfação com o princípio proposto. Já na Ásia, todos os respondentes (8) afirmaram concordar. Na América do Norte e Central, as opiniões estão divididas: 6 concordavam e 7 discordavam.

Verifica-se novamente que 5 das 6 empresas de auditoria são contra o princípio geral proposto, sendo que as 5 contrárias são da Europa. No caso das empresas não financeiras, 20 dos 33 respondentes também não concordaram. Entre as associações profissionais e as instituições financeiras, a posição ficou bastante dividida.

Do total de cartas que se manifestaram contrárias (51), 17 argumentaram que, ao determinar o reconhecimento dos direitos e obrigações que decorrem do contrato, o princípio geral está mais voltado para a forma do contrato do que para a substância econômica.

Para a Ernst\&Young, ao mencionar "direitos contratuais" de um negócio, o Exposure 
Draft 09 estaria redefinindo o conceito de ativo, ao restringi-lo apenas aos direitos que decorrem de um contrato. A carta do The Institute of Chartered Accountants of Scotland também levanta essa discussão e corrobora esse argumento.

Tabela 4 - Posicionamento dos respondentes sobre o Princípio Geral

\begin{tabular}{|c|c|c|c|c|c|c|c|c|}
\hline & \multicolumn{4}{|c|}{ América do Norte e Central } & \multicolumn{4}{|c|}{ Europa } \\
\hline & Concorda & Discorda & $\mathbf{N R}^{1}$ & Total & Concorda & Discorda & $\mathbf{N R}^{1}$ & Total \\
\hline Boards e reguladores & 3 & 0 & 0 & 3 & 7 & 13 & 2 & 22 \\
\hline Associações profissionais & 0 & 1 & 0 & 1 & 5 & 6 & 3 & 14 \\
\hline Inst. Financeiras & 0 & 1 & 0 & 1 & 3 & 3 & 3 & 9 \\
\hline Empresas não financeiras & 1 & 5 & 0 & 6 & 8 & 15 & 2 & 25 \\
\hline Empresas de auditoria & 1 & 0 & 0 & 1 & 0 & 5 & 0 & 5 \\
\hline Acadêmicos & 0 & 0 & 0 & $\mathbf{0}$ & 1 & 0 & 0 & 1 \\
\hline Outros & 1 & 0 & 0 & 1 & 1 & 1 & 1 & 3 \\
\hline \multirow[t]{3}{*}{ Total } & 6 & 7 & $\mathbf{0}$ & 13 & 25 & 43 & 11 & 79 \\
\hline & \multicolumn{4}{|c|}{ Ásia } & \multicolumn{4}{|c|}{ Outros } \\
\hline & Concorda & Discorda & $\mathbf{N R}^{1}$ & Total & Concorda & Discorda & $\mathbf{N R}^{1}$ & Total \\
\hline Boards e reguladores & 8 & 0 & 0 & 8 & 3 & 1 & 0 & 4 \\
\hline Associações profissionais & 0 & 0 & 0 & $\mathbf{0}$ & 1 & 0 & 0 & 1 \\
\hline Inst. Financeiras & 0 & 0 & 0 & $\mathbf{0}$ & 1 & 0 & 0 & 1 \\
\hline Empresas não financeiras & 0 & 0 & 0 & $\mathbf{0}$ & 4 & 0 & 0 & 4 \\
\hline Empresas de auditoria & 0 & 0 & 0 & $\mathbf{0}$ & 0 & 0 & 0 & $\mathbf{0}$ \\
\hline Acadêmicos & 0 & 0 & 0 & $\mathbf{0}$ & 0 & 0 & 0 & $\mathbf{0}$ \\
\hline Outros & 0 & 0 & 0 & $\mathbf{0}$ & 0 & 0 & 1 & 1 \\
\hline Total & 8 & $\mathbf{0}$ & $\mathbf{0}$ & 8 & 9 & 1 & 1 & 11 \\
\hline
\end{tabular}

"Question 2 - Do you agree that a party to a joint arrangement should recognise its contractual rights and obligations relating to the arrangement? If so, do you think that the proposals in the exposure draft are consistent with and meet this objective? If not, why? What would be more appropriate?" (1) NR=Não respondeu.

Ainda, 11 respondentes mencionaram que concordam com o princípio geral, mas não acreditam que as propostas apresentadas no Exposure Draft 09 permitem atingir esse princípio. O ATCO Group (Canadá) argumenta que as alterações propostas não atendem ao princípio geral, pois o método mais adequado para reconhecimento dos direitos e obrigações seria o uso da consolidação proporcional, já que tais direitos e obrigações seriam melhor compreendidos se fossem incluídos nas demonstrações financeiras.

Das 51 cartas que se manifestaram contrárias, 21 mencionaram que o princípio geral é bastante amplo e que precisa de maiores esclarecimentos, com explicações mais profundas sobre alguns termos, para permitir a adequada aplicação do conceito na prática.

Com base nos comentários recebidos, o IASB alterou o princípio geral e, para a emissão da IFRS 11, estabeleceu que a entidade que for parte de um negócio em conjunto deve determinar o tipo de negócio com o qual está envolvida com base na avaliação dos seus direitos e obrigações e reconhecer esses direitos e obrigações conforme o tipo do negócio. Com essa nova redação do princípio geral, o IASB foca mais na substância econômica e não na forma, já que indica que as partes devem reconhecer todos os seus direitos e obrigações que decorrem do negócio em conjunto e que tais direitos e obrigações podem surgir por outros fatores que não apenas o contrato formal.

\subsubsection{Eliminação da consolidação proporcional}

A terceira questão é sobre a eliminação da consolidação proporcional, sendo que essa alteração foi a mais polêmica e a que resultou em impactos mais relevantes nas demonstrações contábeis. Portanto, foi a questão de maior extensão na maioria das cartas. A Tabela 5 apresenta 
a opinião dos respondentes.

Do total de cartas que se manifestaram sobre essa questão (107), a maior parte (68) foi contrária à eliminação da consolidação proporcional. Esse percentual é extremamente relevante e demonstra a polêmica das alterações propostas pelo IASB. É importante mencionar que a consolidação proporcional era uma das principais diferenças que existiam entre as IFRS e as normas contábeis americanas. Para alguns respondentes, o IASB buscou maior convergência com o FASB, porém, às custas da qualidade das informações contábeis.

Novamente, a Europa é o continente com o maior percentual de respondentes que se manifestaram contrários (60 de 76). Nos demais continentes, a quantidade de respondentes favoráveis é maior do que a quantidade de cartas contrárias.

Tabela 5 - Posicionamento dos respondentes sobre a eliminação da Consolidação Proporcional

\begin{tabular}{|c|c|c|c|c|c|c|c|c|}
\hline & \multicolumn{4}{|c|}{ América do Norte e Central } & \multicolumn{4}{|c|}{ Europa } \\
\hline & Concorda & Discorda & $\mathbf{N R}^{1}$ & Total & Concorda & Discorda & $\mathbf{N R}^{1}$ & Total \\
\hline Boards e reguladores & 3 & 0 & 0 & 3 & 4 & 17 & 1 & 22 \\
\hline Associações profissionais & 1 & 0 & 0 & 1 & 2 & 12 & 0 & 14 \\
\hline Inst. Financeiras & 1 & 0 & 0 & 1 & 1 & 8 & 0 & 9 \\
\hline Empresas não financeiras & 1 & 4 & 1 & 6 & 5 & 19 & 1 & 25 \\
\hline Empresas de auditoria & 1 & 0 & 0 & 1 & 1 & 4 & 0 & 5 \\
\hline Acadêmicos & 0 & 0 & 0 & $\mathbf{0}$ & 1 & 0 & 0 & 1 \\
\hline Outros & 1 & 0 & 0 & 1 & 2 & 0 & 1 & 3 \\
\hline \multirow[t]{3}{*}{ Total } & 8 & 4 & 1 & 13 & 16 & 60 & 3 & 79 \\
\hline & \multicolumn{4}{|c|}{ Ásia } & \multicolumn{4}{|c|}{ Outros } \\
\hline & Concorda & Discorda & $\mathbf{N R}^{1}$ & Total & Concorda & Discorda & $\mathbf{N R}^{1}$ & Total \\
\hline Boards e reguladores & 7 & 1 & 0 & 8 & 3 & 1 & 0 & 4 \\
\hline Associações profissionais & 0 & 0 & 0 & $\mathbf{0}$ & 0 & 1 & 0 & 1 \\
\hline Inst. Financeiras & 0 & 0 & 0 & $\mathbf{0}$ & 1 & 0 & 0 & 1 \\
\hline Empresas não financeiras & 0 & 0 & 0 & $\mathbf{0}$ & 3 & 1 & 0 & 4 \\
\hline Empresas de auditoria & 0 & 0 & 0 & $\mathbf{0}$ & 0 & 0 & 0 & $\mathbf{0}$ \\
\hline Acadêmicos & 0 & 0 & 0 & $\mathbf{0}$ & 0 & 0 & 0 & $\mathbf{0}$ \\
\hline Outros & 0 & 0 & 0 & $\mathbf{0}$ & 1 & 0 & 0 & 1 \\
\hline Total & 7 & 1 & $\mathbf{0}$ & 8 & 8 & 3 & $\mathbf{0}$ & 11 \\
\hline
\end{tabular}

"Question 3 - Do you agree that proportionate consolidation should be eliminated, bearing in mind that a party would recognise assets, liabilities, income and expenses if it has contractual rights and obligations relating to individual assets and liabilities of a joint arrangement? If not, why? ” (1) NR = Não respondeu.

Ao analisar por grupo de interesse, tanto para associações profissionais, quanto instituições financeiras, empresas não financeiras e empresas de auditoria, a maior parte dos respondentes se manifestou contrária à eliminação da consolidação proporcional. Para os órgãos reguladores, esse percentual fica dividido: $47 \%$ concordam e 53\% discordam. Considerando-se apenas os órgãos reguladores da Europa, do total de 21 órgãos reguladores que se manifestaram sobre esse item, 17 (81\%) não concordaram com a decisão do IASB.

A Tabela 6 apresenta, de forma resumida, alguns dos principais comentários dos respondentes, tanto dos favoráveis quanto dos que se manifestaram contrários.

Dentre os respondentes que concordam com a eliminação da consolidação proporcional, a maior parte acredita que o MEP realmente reflete melhor a substância econômica do investimento ( 6 cartas) e que o método de consolidação proporcional contraria as definições da Estrutura Conceitual ( 9 cartas) ao permitir que a investidora reconheça ativos que não têm controle integral e passivos que não têm a obrigação presente. Treze cartas argumentam que a investidora de uma joint venture não tem controle integral sobre a investida, tendo direito apenas sobre parcela do resultado gerado pela joint venture. Por fim, vale mencionar que 4 cartas que se manifestaram favoráveis à eliminação da consolidação proporcional justificam a sua posição apenas pelo fato de serem favoráveis à eliminação de escolhas (e não pelo fato de 
um método ser superior ao outro).

Tabela 6 - Comentários sobre a eliminação da consolidação proporcional

\begin{tabular}{l|cc}
\multicolumn{1}{c|}{ Eliminação CP - Comentários } & Favoráveis & Desfavoráveis \\
\hline Favorável à eliminação de escolhas & 4 & 2 \\
\hline MEP reflete melhor a substância do investimento & 6 & 0 \\
\hline CP contraria as definições do framework & 9 & 0 \\
\hline $\begin{array}{l}\text { A investidora não detém o controle integral da joint venture, apenas direitos } \\
\text { sobre o resultado da investida }\end{array}$ & 13 & 0 \\
\hline $\begin{array}{l}\text { Argumentos para a eliminação da CP insuficientes: eliminação de um método, } \\
\text { sem a análise de opções alternativas (MEP ou outras) }\end{array}$ & 0 & 66 \\
\hline MEP também contraria o framework & 0 & 6 \\
\hline CP reflete melhor a realidade econômica (maior relevância) & 0 & 40 \\
\hline $\begin{array}{l}\text { Eliminação de escolhas nem sempre é bom: não permite que os gestores optem } \\
\text { pela prática que melhor reflete a realidade da empresa }\end{array}$ & 1 & 6 \\
\hline Distanciamento entre a contabilidade financeira e gerencial (IFRS 8) & 0 & 18 \\
\hline Não cumpre o item 16 da IAS 01 & 0 & 3
\end{tabular}

Dentre os que não concordam com a eliminação da consolidação proporcional, as justificativas apresentadas são diversas. De forma geral, 66 cartas consideram que o IASB apresenta argumentos insuficientes para a eliminação da consolidação proporcional, já que o Board elimina esse método sem considerar a validade das opções alternativas. O IASB justifica afirmando que analisar a importância e adequação do MEP ou de qualquer outro método alternativo estava fora do escopo do projeto do Exposure Draft 09.

Ainda, 40 argumentam que a consolidação proporcional reflete melhor a realidade econômica do investimento, resultando em informações de maior relevância. Nesse sentido, cabe mencionar que 6 cartas acreditam que nem sempre a eliminação de escolhas é algo positivo, já que essa eliminação impossibilita que os gestores optem pela prática que melhor reflete a realidade da empresa. Apesar de não ser um número significativo (6 cartas), alguns respondentes mencionaram que o uso do MEP também contraria a Estrutura Conceitual, já que não permite a representação fidedigna das informações contábeis.

Além disso, 18 cartas mencionaram que essa eliminação distancia a contabilidade financeira da gerencial, contrariando os objetivos do IASB de aproximação (IFRS 8 Operating Segments). As empresas que utilizam informações da consolidação proporcional para tomada de decisão terão que elaborar um tipo de informação para fins internos e outro para fins de divulgação ao usuário externo, gerando custos adicionais para as empresas. No Brasil, a Companhia Siderúrgica Nacional (CSN) é um exemplo de empresa que, mesmo após a eliminação da consolidação proporcional, optou por continuar a apresentar as suas informações por segmento operacional utilizando a consolidação proporcional das empresas controladas em conjunto, já que esse tipo de informação que é utilizada para tomada de decisão. Além do Brasil, também foram encontradas empresas na África do Sul, no Canadá e no Reino Unido.

Por fim, mesmo que poucas cartas tenham mencionado, vale destacar o fato de que o IASB pode estar contrariando o item 18 da IAS 01 - Presentation of Financial Statements, que afirma que a empresa não pode compensar o uso de práticas inadequadas com divulgações em notas explicativas. Quer nos parecer que o IASB estaria "compensando" a falta informacional das demonstrações contábeis, decorrente da eliminação da consolidação proporcional, com divulgações excessivas em notas explicativas.

Apesar das diversas críticas recebidas, o IASB manteve sua decisão de que todos os investimentos em joint ventures devem ser reconhecidos pela equivalência patrimonial. 


\subsubsection{Exigências de divulgação}

A quarta questão é sobre o nível de disclosure proposto no Exposure Draft 09. Dentre as justificativas do IASB para eliminar a consolidação proporcional, uma delas é que o maior nível de exigência de divulgação nas notas explicativas, sobre os investimentos em joint venture, compensará a perda informacional ocasionada pela eliminação.

A Tabela 7 apresenta a distribuição do posicionamento dos respondentes, conforme o país de origem e o grupo de interesse. A maior parte concorda com o nível de disclosure (68 cartas), considerando que as exigências propostas capturam de forma adequada as questões mais relevantes, aumentando o poder informacional para o usuário das informações contábeis.

Tabela 7 - Posicionamento dos respondentes sobre o nível de divulgação

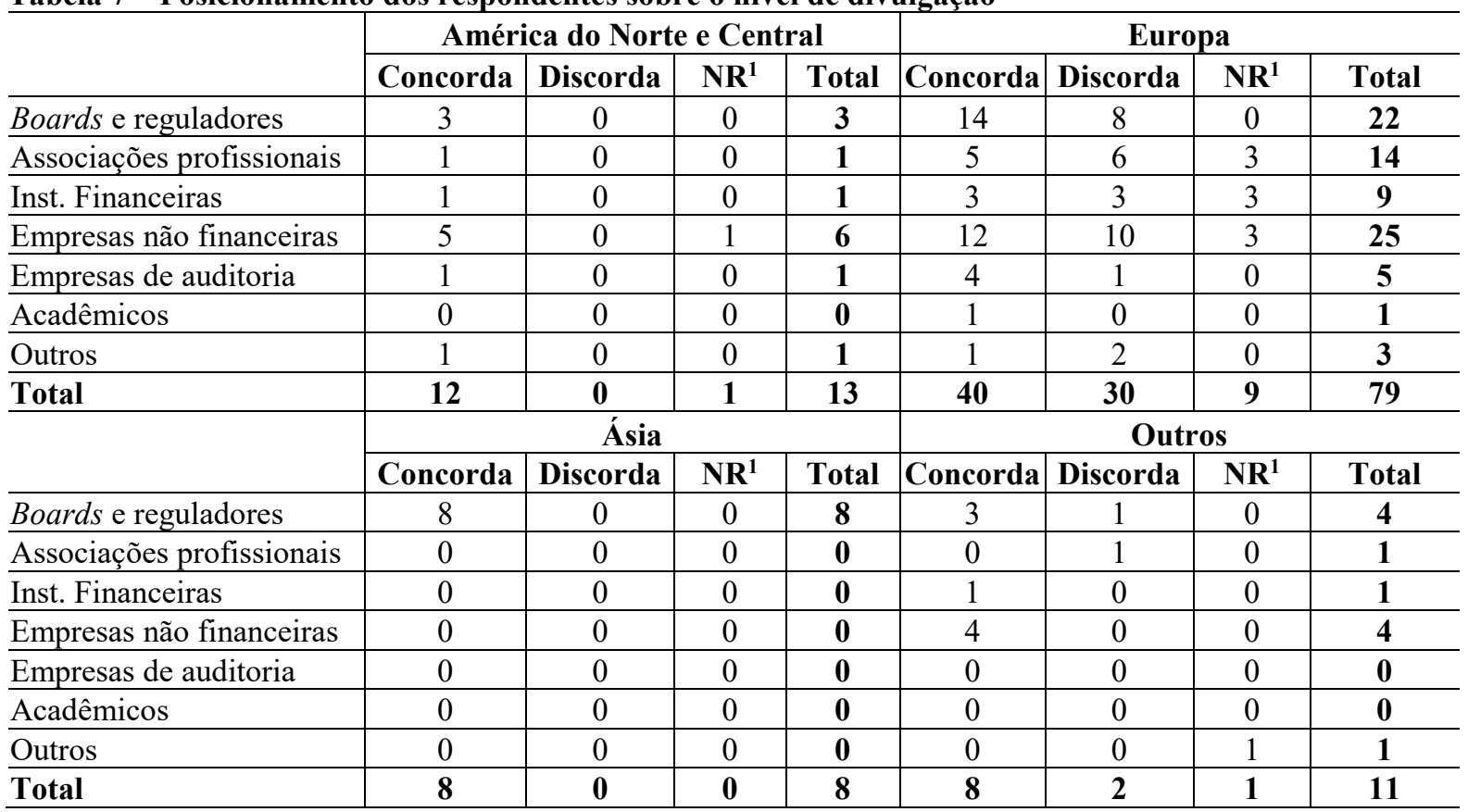

"Question 4 - "Do you agree with the disclosure proposed for this draft IFRS? If not, why? Are there any additional disclosure relating to joint arrangements that would be useful for users of financial statements?"

(1) NR = Não respondeu

Por outro lado, um número razoável de respondentes (32 cartas) não concorda com a eliminação da consolidação proporcional e acredita que o nível exagerado de disclosure resultará em uma quantidade excessiva de notas explicativas, sem agregação de valor, já que não compensará a perda informacional da eliminação da consolidação proporcional.

Apesar do argumento do IASB de que todas as informações que antes eram obtidas com a consolidação proporcional agora podem ser obtidas por meio das notas explicativas, é fundamental mencionar que a divulgação em notas explicativas não é a mesma coisa que apresentar tais informações no próprio corpo das demonstrações contábeis. Os investidores não avaliam da mesma forma essas informações. Para Jifri e Citron (2009), os investidores podem estar desvalorizando as informações divulgadas em notas explicativas tanto por falta de conhecimento, quanto pelo custo de processar essas informações que não são diretamente obtidas nas demonstrações contábeis.

Ainda, é válido destacar uma das principais críticas que os relatórios contábeis vêm recebendo: as notas explicativas estão excessivamente longas, porém, sem poder informacional para os usuários das informações contábeis.

Com base nos comentários recebidos, o IASB mudou algumas das exigências de divulgação, como por exemplo, a possibilidade de apresentar de forma agrupada as informações 
das joint ventures que não forem individualmente relevantes. Ainda, é importante mencionar que as exigências de divulgação de informações sobre os investimentos em joint ventures passaram a ser especificadas pela IFRS 12 -Disclosure of Interests in Other Entities.

\subsubsection{Outros assuntos}

Além das questões que foram sugeridas pelo próprio IASB no Exposure Draft, dois outros assuntos foram frequentemente abordados pelos respondentes. O primeiro deles está relacionado com o fato do IASB tratar da mesma forma dois investimentos que apresentam características bastante diferentes: investimentos em joint ventures e em coligadas.

Do total de cartas enviadas, 33 mencionaram que o IASB assume uma posição equivocada ao tratar esses dois investimentos pelo MEP, já que o nível de envolvimento da investidora na investida é maior quando existe o controle compartilhado do que quando existe a influência significativa. Assim, a contabilização desses dois investimentos deveria ser diferente. O IASB argumenta que o fato de se utilizar o mesmo método não significa que controle conjunto e influência significativa representam a mesma coisa, sendo que as diferenças nas exigências de divulgação para os investimentos em joint ventures e coligadas refletirão essa diferença.

O segundo assunto está relacionado com o objetivo de convergência com o FASB, já que a consolidação proporcional era um dos principais itens divergentes entre os dois órgãos reguladores. Entretanto, 51 cartas argumentam que esse objetivo do IASB não será atingido, já que surgiriam outras diferenças entre as normas internacionais (IFRS) e as americanas (USGAAP), como por exemplo, o fato do FASB permitir o uso da consolidação proporcional para alguns setores de atividade, como o de extração de recursos minerais e construção civil.

\subsubsection{Avaliação da adequação da decisão do IASB}

Com base nas discussões abordadas no referencial teórico e nos argumentos apresentados pelos respondentes que se manifestaram durante o período de audiência pública do Exposure Draft 09, a finalidade deste tópico é inferir a respeito da adequação ou não da decisão do IASB de eliminar a consolidação proporcional e sobre suas possíveis consequências.

Mesmo que a consolidação proporcional possa apresentar algum conflito com os conceitos de ativo e passivo da Estrutura Conceitual, a presente pesquisa argumenta que esse método produz informações contábeis mais relevantes para os usuários do que o MEP, principalmente por impossibilitar que as empresas investidoras se utilizem dos investimentos em joint ventures para manter dívidas fora de suas demonstrações contábeis. É nossa opinião que a consolidação proporcional melhor reflete a situação econômico-financeira das investidoras e, portanto, pode produzir informações de maior utilidade para o processo de tomada de decisão dos usuários das informações contábeis.

Mesmo que as investidoras em conjunto não possuam obrigações legais sobre os passivos da joint venture, elas podem ter, mesmo que indiretamente, obrigações construtivas sobre o desempenho financeiro dessa joint venture, sendo corresponsáveis pelas dívidas da mesma. Tais obrigações afetam a situação econômico-financeira das investidoras e, portanto, deveriam ser reconhecidas em suas demonstrações contábeis.

O caso da Samarco ilustra bem uma das fragilidades do MEP e, portanto, uma das possíveis consequências práticas indesejadas que podem surgir em decorrência da decisão do IASB de eliminação da consolidação proporcional. A Vale menciona na sua própria demonstração contábil que, conforme legislação brasileira e os termos do acordo da joint venture, a Vale não tem a obrigação de prover recursos para a Samarco. Assim, seguindo as determinações da IFRS 11, a Vale não teria direitos sobre os ativos e obrigações sobre os 
passivos da Samarco e, portanto, o MEP foi utilizado.

Porém, com a pressão social, a reputação da Vale e da BHPB também foram afetadas com o desastre ambiental ocasionado pelo rompimento da barragem de rejeitos da Samarco. Como consequência, as duas investidoras em conjunto, mesmo não tendo a obrigatoriedade legal, estão sendo responsabilizadas judicialmente e ambas passaram a ser corresponsáveis, mesmo que indiretamente, pelas obrigações da Samarco. Obrigações essas que não estavam sendo reconhecidas nas suas demonstrações contábeis.

A Vale, em conjunto com a BHPB e a Samarco, estão sendo objeto de ação civil pública movida tanto pelo Governo Federal quanto pelo Ministério Público Federal. Caso a Samarco não cumpra com as obrigações decorrentes do Acordo com os autores da ação civil pública, a Vale e a BHPB serão responsáveis na proporção de suas participações na Samarco (50\% cada). Ainda, na nota 21 da demonstração anual de 2016, a Vale menciona que "fundos para manutenção das operações da Samarco estão sendo liberados pelos acionistas à medida que forem necessários". Ou seja, mesmo que as dívidas sejam da joint venture e que as investidoras, teoricamente, só teriam direitos sobre os ativos líquidos da joint venture, no final das contas elas também acabam sendo corresponsáveis pelas operações da joint venture.

Um indício de que a consolidação proporcional produz informações contábeis de maior relevância para os usuários das informações contábeis é que existem empresas que mesmo após a adoção da IFRS 11 e a obrigatoriedade de utilização do MEP, continuam a divulgar de forma voluntária e adicional as informações contábeis que seriam obtidas pela consolidação proporcional. Especificamente, foram encontradas empresas que divulgam as informações pela consolidação proporcional (proforma) no próprio Relatório da Administração, na nota de informações por segmento operacional, que deve ser elaborada com base nas informações que são utilizadas para fins gerenciais, ou até mesmo como informação adicional.

Essas empresas argumentam que a administração continua a monitorar o desempenho da empresa com base na consolidação proporcional das joint ventures, já que tais joint ventures fazem parte das operações da empresa. Portanto, as informações obtidas pela consolidação proporcional continuam a ser utilizadas no processo de tomada de decisão gerencial, mesmo após a IFRS 11, já que tal método melhor reflete o desempenho econômico-financeiro dessas empresas. Conforme mencionado no Tópico 4.2.4, uma das principais críticas à decisão do IASB de eliminar a consolidação proporcional foi justamente o fato de que isso distanciaria as informações utilizadas para fins gerenciais das informações financeiras divulgadas nas demonstrações contábeis.

Foram encontradas empresas não apenas no Brasil (Companhia Siderúrgica Nacional, Cosan, Bradesco e Klabin), mas também na África do Sul (African Rainbow Minerals), no Canadá (AKITA Drilling, Glacier Media e GVIC Communications) e no Reino Unido (Hammerson, Rurelec, Tate \& Lyle, Telford Homes, Intu Properties e John Wood Group).

Por fim, é importante mencionar que um dos argumentos apresentados pelo IASB é que as exigências de divulgação de informações adicionais sobre as joint ventures, em nota explicativa, compensariam a perda informacional causada pela eliminação da consolidação proporcional. Entretanto, a presente pesquisa argumenta que isso pode não ser totalmente verdade. Primeiro porque os usuários das informações contábeis podem atribuir um peso menor para as informações que são divulgadas em nota explicativa do que as informações que são obtidas no próprio corpo das demonstrações contábeis. Segundo, as empresas nem sempre cumprem com as exigências de divulgação, sendo esperado que as empresas divulguem apenas algumas das informações requeridas. Terceiro, pelo fato de os investimentos em joint ventures serem reconhecidos pelo mesmo método que os investimentos em coligadas, observou-se que algumas empresas passaram a divulgar as informações sobre esses dois investimentos de forma agrupada ("investimentos mensurados pelo MEP" ou "investimentos não consolidados"), sem identificar quais seriam os investimentos em joint ventures e quais seriam os investimentos em 
coligadas. Acredita-se, portanto, que as exigências de divulgação de informações adicionais, previstas na IFRS 12, não compensarão a perda informacional causada pela eliminação da consolidação proporcional.

Com o propósito de verificar se as empresas estão cumprindo ou não com as exigências de divulgação da IFRS 12, foram analisadas as demonstrações contábeis do ano de 2016 das 88 empresas brasileiras que tinham investimentos em joint ventures e que tiveram que trocar da consolidação proporcional para o MEP quando da adoção da IFRS 11. Dessas 88 empresas, apenas 46 divulgaram em nota explicativa as informações sobre os ativos, passivos, receita e lucro líquido das joint ventures. Ou seja, aproximadamente $50 \%$ das empresas analisadas não divulgaram as informações mínimas para que os usuários das informações contábeis pudessem estimar qual seria o valor reportado pela consolidação proporcional. Essa situação também foi observada em outros países, como a França, em que a quantidade de empresas que não divulgaram as informações sobre os ativos, passivos, receita e lucro líquido das joint ventures foi ainda maior. Essas empresas acabam divulgando apenas o valor do investimento e o valor do lucro líquido da joint venture, porém, tais informações são limitadas e, em nossa opinião, não compensam a perda informacional causada pela eliminação da consolidação proporcional.

\section{Conclusões e Considerações Finais}

O objetivo da presente pesquisa foi analisar os argumentos apresentados pelos respondentes que se manifestaram durante o período de audiência pública do Exposure Draft 09 - Joint Arrangements, tanto conforme o grupo de interesse quanto o local de origem. Com base nesses argumentos, esta pesquisa também buscou inferir sobre a adequação da decisão do IASB de eliminar a consolidação proporcional como uma alternativa válida para reconhecimento dos investimentos em joint ventures e sobre suas possíveis consequências.

Para atingir esse objetivo, as 111 cartas que foram enviadas para o IASB durante o período de audiência pública do Exposure Draft 09 foram analisadas por meio da técnica de Análise de Conteúdo. Os resultados indicaram que das 111 cartas recebidas pelo IASB, 67 afirmaram já no início que não concordam com a emissão da IFRS 11 da forma como proposta no Exposure Draft 09. Em relação aos conceitos e terminologias e ao princípio geral, observouse bastante divergência de opiniões. Por outro lado, as exigências de divulgação propostas receberam aceitação por $68 \%$ dos respondentes. Entretanto, para a decisão do IASB de eliminar a consolidação proporcional, que foi a principal alteração proposta no Exposure Draft 09, o nível de rejeição foi bastante elevado (64\%): das 107 cartas que se pronunciaram sobre essa questão, 68 afirmaram não concordar com a decisão do IASB. Esse número demonstra a polêmica causada pelas alterações propostas pelo IASB e também pode ser considerado um indício de que a decisão de eliminar a consolidação proporcional pode não ter sido adequada.

Ao analisar o local de origem dos respondentes, identificou-se que os países com maior taxa de rejeição às alterações propostas pelo IASB estão na Europa, seguidos pela América do Norte e Central. Do lado oposto, os países da Ásia foram os que apresentaram maior percentual de aceitação. De forma semelhante, os grupos de interesse que apresentaram maior rejeição às propostas do IASB foram as empresas de auditoria e as associações profissionais.

Dentre os respondentes que se manifestaram contrários à decisão do IASB de eliminar a consolidação proporcional, a maioria menciona que o IASB apresentou argumentos insuficientes para justificar tal eliminação (66 cartas) e que a consolidação proporcional resulta em informações contábeis de maior relevância (40 cartas).

Apesar da elevada taxa de rejeição e de todas as críticas recebidas, o IASB manteve a sua decisão de eliminar a consolidação proporcional quando da emissão da IFRS 11 propriamente dita. Alguns respondentes inclusive mencionaram que o IASB buscou maior convergência com o FASB, porém, às custas da qualidade das informações contábeis. 
Com base nos comentários e percepções desses respondentes, bem como os pontos positivos e negativos de cada um dos métodos, a presente pesquisa argumenta que a consolidação proporcional resulta em informações contábeis mais relevantes do que o MEP, pois melhor refletem o desempenho econômico-financeira das empresas investidoras. Nesse sentido, acredita-se que a decisão do IASB de eliminar a consolidação proporcional pode resultar em consequências práticas indesejadas, já que permitirá que as empresas investidoras mantenham fora do balanço dívidas que comprometem a sua situação financeira.

As investidoras em conjunto podem ser corresponsáveis pelas dívidas da joint venture, mesmo que indiretamente e mesmo que não seja uma obrigação legal, e isso pode afetar a sua situação financeira. Tais obrigações deveriam estar refletidas nas demonstrações contábeis das investidoras. O desastre ambiental ocorrido em 2015, com o rompimento das barragens de rejeitos da Samarco, corrobora esse argumento. Mesmo não tendo obrigações legais de prover recursos para a Samarco, tanto a Vale quanto a BHPB estão sendo responsabilizadas judicialmente e passaram a ser corresponsáveis sobre as operações e, principalmente, sobre as dívidas da Samarco, conforme discutido ao longo deste trabalho.

Adicionalmente, a presente pesquisa também argumenta que as exigências de divulgação de informações adicionais sobre os investimentos em joint ventures, conforme determinações da IFRS 12 - Disclosure of Interests in Other Entities, não compensarão a perda informacional ocasionada pela decisão do IASB de eliminar a consolidação proporcional.

Acredita-se que as discussões aqui apresentadas são relevantes e tempestivas, já que o IASB incluiu na sua agenda a intenção de iniciar o Post-Implementation Review (PIR) da IFRS 11 (em conjunto com a IFRS 10 e 12). Assim, espera-se que este trabalho contribua não apenas para a literatura contábil sobre o método mais adequado para reconhecimento dos investimentos em joint ventures, mas principalmente para os órgãos reguladores, ao fornecer indícios que o IASB poderá levar em consideração durante o PIR da IFRS 11, para avaliar se a sua decisão de eliminar a consolidação proporcional foi adequada ou não.

\section{Referências}

BARDIN, Laurence. Análise de Conteúdo. Lisboa: Edições 70, 1977.

BETANCOURT, Luis; BARIL, Charles P. Accounting for Joint Ventures moves closer to convergence. The CPA Journal, v. 83, n. 2, p. 26-31, 2013.

FURUTA, Fernanda. Estudo da consolidação proporcional nas empresas que atuam no mercado brasileiro. 2005. 151 f. Dissertação (Mestrado em Controladoria e Contabilidade). Programa de Pós-Graduação em Controladoria e Contabilidade, Universidade de São Paulo, São Paulo, 2005.

GRAHAM, Roger C.; KING, Raymond D.; MORRILL, Cameron K. Decision usefulness of alternative joint venture reporting methods. Accounting Horizons, v. 17, n. 2, p. 123-137, 2003. DOI: https://doi.org/10.2308/acch.2003.17.2.123

JIFRI, Khaled Al; CITRON, David. The value-relevance of financial statement recognition versus note disclosure: evidence from goodwill accounting. European Accounting Review, v. 18, n. 1, p. 123-140, 2009. DOI: https://doi.org/10.1080/09638180802324351

KRIPPENDORFF, Klauss. Content Analysis: An Introduction to its Methodology. California: SAGE Publications, 2004. 
LEITNER-HANETSEDER, Susanne; STOCKINGER, Markus. How does the elimination of the proportionate consolidation method for joint venture investments influence European companies? ACRN Journal of Finance and Risk Perspectives, v. 3, n. 1, p. 1-18, 2014.

LOURENÇO, Isabel Costa; CURTO, José Dias. Determinants of the accounting choice between alternative reporting methods for interests in jointly controlled entities. European Accounting Review, v. 19, n. 4, p. 739-773, 2010. DOI:

https://doi.org/10.1080/09638181003687844

GELBCKE, Ernesto Rubens; SANTOS, Ariovaldo; IUDÍCIBUS, Sérgio; MARTINS, Eliseu. Manual de Contabilidade Societária: Aplicável a todas as sociedades. $3^{\mathrm{a}}$ ed. São Paulo: Atlas, 2018.

MILBURN, J. Alex; CHANT, Peter D. Reporting interests in joint ventures and similar arrangements. Norwalk: Financial Accounting Standards Board, 1999.

NOBES, Christopher. The continued survival of international differences under IFRS. Accounting and Business Research, v. 43, n. 2, p. 83-111, 2013. DOI: https://doi.org/10.1080/00014788.2013.770644

REKLAU, David L. Accounting for investments in joint ventures - a reexamination. The Journal of Accountancy, v. 144, n. 3, p. 96-103, 1977.

RICHARDSON, A. William; ROUBI, Raafat R.; SOONAWALLA, Kazbi. Decline in financial Reporting for joint ventures? Canadian evidence on removal of financial reporting choice. European Accounting Review, v. 21, n. 2, p. 373-393, 2012. DOI:

https://doi.org/10.1080/09638180.2011.558298

SACCON, Chiara; DIMA, Ştefana Maria. Financial reporting for joint ventures and capital markets reactions. International Journal of Economics and Business Research, v. 9, n. 2, p. 158-169, 2015. DOI: https://doi.org/10.1504/IJEBR.2015.067363

SANTOS, José Augusto Filipe da Costa. Tratamento contabilístico dos interesses em entidades conjuntamente controladas nos sectores da construção e do real estate. 2011. 56 f. Dissertação (Mestrado em Contabilidade). ISCTE-IUL, Lisboa, Portugal, 2011.

SARQUIS, Raquel Wille; SANTOS, Ariovaldo. Impactos da eliminação da consolidação proporcional nas demonstrações contábeis da Itaúsa. Revista Contabilidade \& Finanças, v.29, n. 77, p. 213-228, 2018. DOI: http://dx.doi.org/10.1590/1808-057x201804470

SARQUIS, Raquel Wille. Diferenças nas práticas contábeis na era IFRS: implicações para a comparabilidade das informações financeiras em ambientes diferentes. 2019. 787 f. Tese (Doutorado em Controladoria e Contabilidade). Programa de Pós-Graduação em Controladoria e Contabilidade, Universidade de São Paulo, São Paulo, 2019.

SOUZA, Jocely Alves; TAVARES, Márcia Ferreira Neves; ANJOS, Luiz Carlos Marques; LOPES, Christianne Calado Vieira de Melo. Uma análise da extinção da consolidação proporcional em investimentos joint ventures a partir da perspectiva das empresas que contribuíram junto ao IASB. Revista de Contabilidade da UFBA, v. 9, n. 3, p. 18-34, 2015. 